\title{
Knowledge Construction in an Australian Software Development Enterprise: Developing the Knowledge Bases for Innovative Renewal
}

\author{
Richard White \\ CEO: Eagle Datamation International \\ P. O. Box 665, Mascot. NSW 1460. Australia \\ Tel. 61 - 2 - 90251101 \\ Email: richard@edi.com.au
}

and

\author{
Ken Dovey \\ Associate Professor: University of Technology, Sydney \\ P. O. Box 123, Broadway. NSW 2007. Australia \\ Tel. 61 - 2 - 95147937 \\ Email: kend@it.uts.edu.au
}

\section{Authors’ Biographical Details}

Richard White is the CEO, founder, and principal shareholder of Eagle Datamation International (EDI), a medium-size organization in Sydney, Australia that develops software for the global customs brokerage and freight-forwarding market. He holds a Masters degree in Business from the University of Technology, Sydney in Australia.

Dr Ken Dovey is Director of the Information Technology Management Programme (ITMP) in the Faculty of Information Technology at the University of Technology Sydney (UTS), in Sydney, Australia. Formerly, he held the Chair in Leadership Studies and directed the Johnson \& Johnson Leadership Development Institute at Rhodes University in South Africa. Over the past twenty years, he has lectured at numerous universities around the world and has been a consultant on leadership and organisational development and change to many organisations including global corporations such as Johnson \& Johnson and DaimlerChrysler. 


\title{
Knowledge Construction in an Australian Software Development Enterprise: Developing the Knowledge Bases for Innovative Renewal
}

\begin{abstract}
This paper describes the transformation of a software development organization in Australia and theorizes the learning and knowledge construction processes which this entailed. Faced with changes to the regulatory environment of the organization, key stakeholders engaged in the processes of learning how to create the conditions under which a new 'insurgent' organization, focused upon innovation, could emerge from the old 'incumbent' organization without disruption to revenue flows during the twoyear transitional period. The paper explicates these learning processes, and the form of praxis that underpinned them, and shows the critical role played by external stakeholders, such as customers, to the success of the praxis. A key insight gained from the project was the crucial role played by social capital - in particular, relational and identity resources - in the collaborative learning practices through which knowledge, relevant and pertinent to the purpose of the project, was constructed and is being re-constructed as the contexts of its application transform.
\end{abstract}

Key Words: knowledge construction; social capital; creative destruction; collaboration; innovation; organizational renewal 
This paper describes and theorizes the transformation of a software development company in Australia in response to impending changes in its regulatory environment. Although profitable and dominant in its niche Australasian freight forwarding and customs brokerage software market, the company needed to transform itself from a complacent 'incumbent', focussed on operational excellence, into a challenging 'insurgent', focussed on innovation. In broad terms, the transformation required organizational leadership that could apply Schumpeter's theory of 'creative destruction' and focus on the creation of 'learning contexts' in which the requisite knowledge would be constructed [1].

We hope to contribute to existing theoretical perspectives by means of an analysis of the role of social capital as a means to producing the collaboration required for the construction of knowledge and innovation. We argue that social capital theory offers a valuable explanatory framework for organizational transformation, and that strategic leadership practices need to facilitate the development of all three dimensions of social capital - structural, cognitive, and relational - for transformation to be successful. Furthermore, we argue that facilitative learning contexts are characterized by a form of praxis whereby the dialectical relationship between theory and action, context and cognition, individual and community, strategy and purpose, is recognized and sustained for the duration of any knowledge-construction endeavour.

\section{Background to the Study}

By November 2001, after eight years of consistent growth, Eagle Datamation International (EDI) had risen to dominance (70\% market share) in the Australasian market for freight forwarding and customs brokerage software. The primary source 
of this success had been its legacy product, Deliverance, but proposed regulatory changes to the industry meant that a new product line had to be developed within a two-year time frame if EDI was to sustain its local dominance and extend it beyond Australasia.

This strategic inflection point in EDI's competitive situation provided the impetus for the CEO to transform EDI's strategy to one based upon ongoing innovation [2]. However, given EDI's dependence during this period of transformation on the revenues generated from its legacy product, the operational excellence of the 'old' organization would have to be managed simultaneously with the transformation of the business, and the requisite knowledge would have to be developed in situ [3].

The strategic transformation was preceded by a lengthy period of discussion and analysis by the CEO and the university- based learning facilitator on the nature of knowledge. Consensus was reached on the assumption that knowledge is grounded in human interests, and that therefore knowledge construction in organizations is a means of serving stakeholder interests. These interests would transform concurrently with the contexts that give them meaning, and therefore the knowledge that serves them would be emergent - it would not develop into a fixed state but would always be a 'work in progress'. Knowledge would be constructed as it was required, through the dialectical relationship between the context and the stakeholder interests that inform that context.

The alignment of multiple and shifting social contexts and stakeholder interests would require strategic vigilance and high levels of commitment from all stakeholders. Such 
commitment would be generated by the alignment of the project mission with the personal purpose and interests of these stakeholders.

In order to leverage the knowledge resources embedded in the knowledge-interests of the stakeholders and in the social contexts of their relationships with each other, particular forms of relationship and communication would need to be facilitated by the Odyssey project. This led to the choice of a form of praxis - a collaborative form of action and critique - as the most appropriate learning methodology for the project. Through praxis, 'grounded' theory developed from experience would continuously inform, and transform, existing theoretical frames of reference in ways that would uphold the theory-action dialectic [4]. Such processes would ensure that the tacit knowledge generated through experience (action) and shared through processes of socialization amongst project stakeholders, is made explicit through collaborative articulation processes. Once explicit, such insights can be refined into precise terms that are able to re-form the theoretical frameworks that guide the strategic direction of the project in order to ensure that knowledge that is relevant and pertinent to a regularly re-viewed mission is constructed [5].

\section{Framing the Strategic Action}

The transformation of EDI into an innovation-focussed organization involved two main strategies. The first of these was that of 'creative destruction' - the destruction of the old business while it was still profitable and the creation, within its midst, of a new business that would ensure the long-term survival of the organization. Rather than attempting to transform the old business through the creation of an off-site 'skunkworks', the CEO chose the more difficult strategy of developing new 
innovative capabilities within the existing operating context of EDI [6]. As an established 'incumbent', EDI had developed a culture of complacency and the CEO decided that rather than attempt the difficult and slow task of transforming the mental models, or sets of assumptions about themselves, others and 'the way the world works', of existing staff, he would recruit new staff for the development of the new business [7].

The second strategy was the creation of appropriate learning contexts for the new business - represented by the Odyssey project - wherein the knowledge required for the successful implementation of the mission would be constructed. The catch-phrase 'the strategy is the culture' was coined by the CEO as the guiding principle in this respect. The culture was to be created through the location of talented software developers within a flat, team-based, structure; the use of an agile programming methodology known as Extreme Programming (XP); and through a set of selfmanagement practices intended to create the conditions for authentic collaboration among them. Through this culture the CEO hoped to sustain creativity amongst these empowered individuals for periods long enough to enable its conversion into innovative products and services.

\section{The First Phase of the Praxis}

The newly recruited team of eight software developers was located at one end of EDI's large open-plan office, and was issued with t-shirts bearing the Odyssey logo. This was part of the strategy of creating a unique identity for the team and signaling to the other staff the special status of the project. The CEO, as a member of the Odyssey team, had his desk relocated to the centre of the team's work area. 
The CEO briefed the team on the mission of the project, which was the replacement, within two years, of the legacy product, Deliverance, by a new web and desktop enabled suite of products aimed a global market. In order to achieve this, the team was empowered to the point of self-management and would be given all the resources it needed.

No explanation for the introduction, and special treatment, of the Odyssey team was offered to the 'old' EDI staff by the CEO. Rather than trying to persuade members of staff about the need for cultural change at EDI, the strategy of the CEO was to tacitly appeal to them to voluntarily 'migrate' to the project; an act through which they would be demonstrating the flexibility of their orientation to work and learning, and thus their suitability for membership of the new EDI culture.

After two months, the first formal analysis of the project action took place. This analysis incorporated a series of discussions amongst the team members and a set of interviews with members by the university-based observer. From these, it became clear that the initial theoretical framework for the strategic action was not delivering the anticipated results and that the team was not exploiting the potential of a flat organizational form. Despite their excellent technical skills the new recruits were demonstrating inflexibility of mind, limited capacity to collaborate and, as a consequence of years of socialization in technology-orientated settings, inappropriate assumptions concerning knowledge construction. This had resulted in little work of value being produced during the first two months of the project and personality clashes and power struggles within the team. The more experienced members were 
calling for the installation of a supreme coach - someone who would provide overall direction and have ultimate technical authority in the team.

Two other important issues emerged from the interviews conducted by the universitybased observer. Firstly, despite the original briefing, few members of the team understood the Odyssey mission, and thought that it was to upgrade the legacy product, Deliverance. No follow-up work had been done to ensure their understanding of it or its relevance to each member's personal interests. As a consequence, the mission was not working as a mobilizing and unifying force amongst team members.

Secondly, the interviews showed that the developers were preoccupied with technical aspects of their work and that the primary source of work satisfaction was task related. Generally, learning within the project appeared to be a predominantly individual endeavour, restricted to technical forms of learning, and narrowly focussed on functional, as opposed to strategic, activities.

The results of the first formal analysis of the project indicated that three inappropriate assumptions were undermining its implementation. In the first instance, a central power culture was an historical feature of EDI, with the CEO dominating all decisionmaking within the company [8]. Furthermore, his clear technical superiority over all other staff had resulted in what he colloquially referred to as, a 'truck factor of 1' (the number of people in the organization who would have to be hit by a truck in order for the organisation to fail). In an organization totally dependent upon him, the 
assumption that all he had to do was to create a team structure and leave it to the members to exploit the resultant culture for innovative purposes, was flawed.

Secondly, whilst structure will normally facilitate the development of a particular culture over time, in rapidly changing environments this process needs to be accelerated. Given the time frame, the assumption that the structure alone would create the learning contexts through which the mission-critical knowledge would be constructed was inappropriate. Thus the need for leadership practices able to accelerate the development of strong relationship bonds, profound levels of communication, and a sense of shared purpose among stakeholders (as articulated in the discussions prior to the project) was overlooked in the implementation of the first phase of the praxis.

Thirdly, around this time, a fortuitous observation by the CEO contributed a key insight into the failure of the Odyssey team to deliver expected results. Outside the Odyssey team, a programmer who had experienced many problems with a product started to show dramatic improvement in his productivity and in the quality of his work. The CEO noticed that these positive changes occurred from the moment that this programmer had engaged real clients with real problems in trying to use his system. In a moment of insight, he realised that an important missing ingredient in the Odyssey team was that of a real customer. Thus, although the importance of customers' knowledge interests and knowledge resources had been recognized in the discussions that framed the first phase of the praxis as crucial to the success of the knowledge construction processes, this issue had been overlooked in the strategic implementation of the project. A key reason for this was the assumption held by the 
team that XP's definition of a customer - one that allowed an 'internal' person such as the CEO to play this role - was adequate.

\section{Re-Forming the Theoretical Frameworks and Re-Newing the Strategic Action}

The key learning gained by the CEO resulted in three immediate actions. Firstly, he introduced the team to the core protocols, a set of practices advocated by McCarthy \& McCarthy that provided for the on-going workshopping of mission, vision and values (or the 'core') in the interests of aligning members' personal 'core' with that of the $\operatorname{project}^{1}[9]$.

Secondly, he introduced morning 'stand-up' meetings that commenced with a 'checkin’ procedure (from the core protocols) in which each team member spoke briefly on their current state of 'emotional being', and whereby a degree of emotional connectedness was achieved between team members at the commencement of work each day. This created the inter-subjective conditions under which a shared future could be debated and discussed and the knowledge interests of team members could be explored, understood and aligned with those of the other team members. In addition, he introduced 'alignment meetings' as social occasions where team members shared their life goals and life scripts. Through the introduction and management of these practices, the CEO accepted an active coaching role in the team with the intention of creating the conditions under which members would take greater ownership of the strategic leadership of the project, and invest greater levels of commitment and energy in the processes of its implementation. The intention was to increase the 'truck factor' of EDI.

\footnotetext{
${ }^{1}$ The process outlined by McCarthy \& McCarthy was judged by the team to be too 'evangelical' for the Australian cultural context and was thus modified appropriately for use in the Odyssey team.
} 
Thirdly, he introduced real customers on a full-time basis to the team. In this way he created opportunities for effective communication between team members and EDI's real customers in order for them to understand the knowledge resources and interests each brought to the knowledge construction encounters.

\section{Analysis of the Second Phase of Strategic Action}

Four months later, a second formal analysis of the project was undertaken. Over this period, an impressive increase in value appeared to have been created through multiple new products that reflected a broad product range, and collaborative product development processes that included real customers. In response to the observation that there seemed to be greater trust between team members, the CEO acknowledged that 'at some indefinable point' the team had 'started to feel like a family'. This had been visible to the observer in the morning 'stand-up' meetings over several weeks, where team members had begun to express their sense of the significance of the project to their professional and personal lives. A growing sense of a covenantal culture - of the Odyssey team having a shared destiny that was important to each of them - was evident in team meetings. Furthermore, whilst members still disagreed on many things, such conflict was oriented around issues central to the purpose of the Odyssey project. This demonstrated the emergence of relationships characterized by the creative abrasion referred to by Leonard-Barton as being essential for the development of an innovation-supporting culture [10].

An incident that occurred during a visit by the observer demonstrated the role of more constructive power management practices by the CEO in creating an optimal learning context. A member of the team lost an entire client database from the company's 
main web system, and when he approached the CEO expecting to be fired the CEO calmly asked him whether he could recover the database. Within a few hours, with encouragement from the CEO, the database had been recovered. The fact that there had been no penalty, emotional or otherwise, for this mistake made a lasting impression on the team member, as he related afterwards to the university-based observer:

After we had fixed the problem, he (the CEO) said to me, 'We should allow people to make mistakes and learn from their mistakes.' This was very valuable for me because after that I felt very secure. I will never forget this. I now feel secure in the team, in the company, and I am motivated to achieve targets.

These observations of the positive development of relationships in the project were supported by the second set of interviews conducted with the eight original team members (by this stage the team had grown in number to fourteen members). In these interviews, team members’ accounts of their daily work experience depicted a culture that promoted knowledge-construction activities and family-like mutual support. The team was described as having developed into a community of friends who take their work, each other, and their responsibilities towards each other, very seriously while simultaneously having fun together. The more experienced programmers commented that the project now provided an ideal work situation. One member said that he could not conceive of a better place to work; another commented that,

The atmosphere we have here could not be found easily somewhere else. It is friendly, we laugh, we kid each other sometimes but we are serious in the work. We have fun at work and I have some very good friends. At our alignment meetings, everybody talks about their goals, what bothers them, what makes them happy, you know, things like that. I tell everybody that I don't like this or I like that and I know that everybody will try to fix these problems. I feel that I am in a dynamic team with people who are concerned, people who care about me, and I feel very good. 
The interviews reflected clarity amongst members that the purpose of the project was the replacement of the legacy freight forwarding software system (Deliverance) by a market-leading application (Odyssey) that will strengthen and expand EDI's share of the global (as opposed to regional) freight forwarding software market. Similarly, with each using almost exactly the same words, members saw a 'team' as a group of people working together towards the attainment of a shared goal. Compared to the situation described in earlier interviews, this clarity and consistency of perception of the mission of the project and of the concept of a team amongst these members, provided strong evidence of the success of the core protocols and other team-building processes introduced by the CEO during the second phase of strategic action in the project.

Furthermore, members perceived a relationship between the concepts of a shared goal and communication. As one member argued, without effective communication collective action cannot be aligned with the shared goal:

The most important aspect of teamwork is good communication. It's number one. If you don't have communication, you don't have a team because unless you have coherent communication within the group, you cannot be sure that you do have a common goal.

Members raised the importance of trust, linking it to the phenomenon of knowing others well. As one member put it, trust involves knowing what you can depend upon someone to do and knowing what you cannot depend upon that person to do:

What is crucial is trust in your team mates, and that goes along with knowledge of them. You know what they can do and you trust they will do what you know they can do. Part of that trust is also knowing what you can't depend on them for. If you know what they can't do, then you know that if you ask them to do something like that, that you have to take on the responsibility of following up on them or helping them out. 
The interviews also provided evidence of members increasingly taking personal responsibility for honouring the trust that other members placed in them:

I think that the most important thing I have learned from being on the Odyssey team is responsibility. I feel a lot of responsibility because people depend on what I do in order to be able to progress the work. When I get a task to do, they trust me to do it well. If I neglect it, or I don't do it well, eventually someone is going to have to come back and fix it up. So, I have accepted the responsibility of doing something well. In order for the whole team to work together effectively each person in the team has to do a good job on exactly what they are responsible to do.

Members showed far greater awareness of social dynamics as a key aspect of successful knowledge construction practices. While technical aspects such as developing new skills, exposure to new technologies, and recognising the benefits of a trade-off between what works and what is technically elegant were still important to them, members were now primarily motivated by more social dimensions of their work. Their membership of a dynamic community of practice that has a common and visible goal, the attainment of which is seen as a personal responsibility, had facilitated a more fulfilling way of working (and living) and this had encouraged within the team a sense of mutual 'ownership' of the project, as one member expressed it:

A while ago Richard (the CEO) was talking about something and he said, 'I want to keep this business going'. I realised then that I want this business to be going as much as he wants it to go because it is my business. I really want to improve the company because I am part of the company. We are a group of people who have the same goal and interests.

As a consequence of this growing capacity amongst all team members to take responsibility for action and to solve problems quickly through self-reflexive work practices and collaborative modes of learning, the locus of action appeared to be shifting from the CEO to the team itself. 


\section{Managing Incompatible Cultures}

By this stage, three camps, which the CEO referred to as the 'In', the 'In-coming', and the 'Out' groups, had developed within EDI. The Odyssey team was 'In'. The 'In-coming' group referred to those 'old' EDI staff attempting to connect to the project in various ways. One Odyssey team member had been given the task of facilitating the entry of these individuals into the team.

A significant number of the 'old' EDI staff, however, remained in the 'Out' group. Feeling betrayed by the CEO, they showed resentment towards the Odyssey project and posed an ethical dilemma for the CEO who, given their loyalty to the company over a significant number of years, felt obligated to continue their employment at EDI.

\section{The Third Phase of Formal Analysis of the Odyssey Project}

Six months later, and one year into the project, the external observer conducted a 'focus group' session with the original Odyssey team members. During this meeting, they claimed that, in spite of the growth of the Odyssey team, the project was on target in terms of its mission and the team was as bonded, and the communication as rich, as that depicted in the previous analysis. 'Stand-Up' meetings and 'Check-Ins' remained a daily practice although there were fewer alignment meetings. Regarding the transformation of EDI as an organization, they claimed that some staff remained outside the Odyssey project and were ignorant of its purpose and relevance.

In an interview with the CEO, he estimated that, at that stage, the Odyssey team comprised approximately thirty-five members; that there were approximately ten staff 
who were 'boundary spanners' (partly 'inside' and partly 'outside’ the team); and ten staff who remained 'outside' the Odyssey project. Of these, he argued that five were constrained by the function they perform, in terms of their capacity to move into the team, while the other five had 'attitude problems' and were unlikely ever to join the Odyssey team. On the ethical-cum-strategic issue of what to do about these staff, he remained unsure.

\section{Evaluation of Mission Implementation One Year into the Odyssey Project}

Thus far a broad range of new software products has been developed with current and potential revenues far in excess of those generated by legacy Deliverance products. Furthermore, new global markets for EDI customs brokerage products have opened recently as a consequence of global political events. For example, the USA, as part of its 'homeland security' drive, is mandating much stricter and more complex international customs requirements. This has put pressure on Asian countries, traditionally slow to take up customs procedures, to adopt more standardized procedures, thereby opening up potential new markets for EDI products.

Regarding the success of the simultaneous management of the two contradictory cultures within EDI over the past year, key financial indicators reflect a healthy situation. Current cash holdings are significantly better than before the start of the Odyssey project (assisted, to some extent, by asset sales), and EDI is still profitable in spite of significant investment in the Odyssey project (especially through the employment of a significant number of additional staff). Just over one year into the Odyssey project, $80 \%$ of EDI's revenue still is derived from Deliverance products 
although this is changing rapidly as new customs regulations become law in Singapore (1 January, 2003) and Australia (1 November, 2003).

\section{Key Learning Gained from the Project Praxis}

The strategic leadership practices involved in the transformation of EDI can best be theorized in the terms provided by social capital theory. Nahapiet \& Ghoshal define social capital as the 'sum of the actual and potential resources embedded within, available through, and derived from the network of relationships possessed by an individual or social unit' [11]. They have identified social capital as relevant in the context of facilitating innovation, pointing out that innovation depends upon resource combination (in terms of internally-held knowledge resources) and exchange (where knowledge resources are held by external parties).

In the context of the transformation of EDI, it was identity social capital resources that generated commitment from members to act for the benefit of the team and that created a learning context able to sustain the necessary spirals of praxis. Where mission-relevant knowledge must be constructed continuously within constantly transforming social contexts of learning, the key issue is not simply how resources are accessed and exchanged, but why stakeholders in the organization should continue to invest in the process. In this respect, it was identity resources that underpinned the capacity of stakeholders to shape and shift their identities in such a way as to facilitate a new sense of their agency, and a willingness and capacity to act for the benefit of the project in new and different roles than their previous perceptions of self allowed. 
The initial phases of planning had put in place two of the three strategic dimensions required for the generation of social capital [12]. The structural and cognitive dimensions were provided for, firstly, in the choice of a team structure, with its emphasis upon equality of status, shared identity, and collective responsibility for results [13]; and, secondly, in the choice of XP methodology with practices such as pair programming and the rotation of programmers within the pairs every three weeks. This facilitated resource combination, reduced the 'stickiness' of tacit knowledge, and developed the absorptive capacity of the collective with respect to knowledge transfer [14]. Working together in this way, team members developed important knowledge resources such as shared languages, codes, experience, mental models, narratives and, thus, compatible world-views - all aspects of the cognitive dimension of social capital.

Most importantly, the structural and cognitive dimensions were provided for in the choice of praxis as the core learning methodology. The ongoing cycles of collaborative action and critique allowed for the sharing of intellectual resources and, in turn, enabled the ongoing transformation of theoretical frames of reference. The structural and cognitive dimensions alone, however, proved to be insufficient to ensure the success of the praxis. What was overlooked initially was the relational dimension of social capital. Although the team had access to everyday face-to-face encounters with each other, the superficial nature of the communication that characterized these encounters failed to build trust - the most critical of all social capital resources. Without trust, other key social capital resources such as shared commitment, norms of reciprocity, voluntary cooperation, and shared identity could not be developed. 
As the Odyssey team was new to EDI, it had no shared historical experience. In the absence of such historical identity resources, it was important to create a sense of 'futuricity'. This required the constant endorsement of a meaningful shared mission and vision of the future (one which offered not only sustainable employment but a life purpose and a creative way of work/life) through the core protocol practices.

The construction of a shared purpose required bonded relationships between team members created by means of opportunities to 'get to know one another' through more profound forms of communication [15]. The introduction of the morning 'stand-up' and evening 'alignment' meetings facilitated such forms of emotionallycharged, inter-subjective engagement among team members. Within a few months, these practices enabled the creation and leveraging of powerful identity resources within the team, and ensured the efficacy of the other two dimensions of social capital. Linked to this was the realisation of the need for similar engagement with stakeholders located outside of the organization (Burt refers to access to network relationships external to the organization, as bridging social capital) [16]. In particular, meaningful engagement with customers, in order to facilitate mutual understanding of knowledge interests, and with the university partner-in-learning with respect to the accurate reading of the praxis, has been recognized as crucial to the success of the project. Thus, both bonding and bridging social capital have proved vital for innovation at EDI as strong links between internal and external networks of knowledge resources were essential for successful stakeholder learning, change, and knowledge construction.. 
The knowledge construction process at EDI shows that without trust, and a powerful shared vision of the future, it is highly unlikely that a group of people will commit to such an intellectually and emotionally demanding task. In this case, where urgent transformation was necessary, the creation and leveraging of social capital resources proved critical to the rapid construction of mission-pertinent knowledge by the Odyssey team. Regarding the role of strategic leadership in the construction of relevant learning contexts for the project, the critical action was that of facilitating the team members' identification with the project's core (mission, vision and values) and of creating opportunities for authentic inter-subjective engagement amongst all stakeholders. However, sustaining the meaningfulness of the learning endeavours for all stakeholders, and thereby ensuring continuous processes of organizational renewal, will require committed strategic vigilance by the entire stakeholder community.

\section{References}

[1] Schumpeter, J. (1939) Business Cycles: A Theoretical, Historical and Statistical Analysis of the Capitalist Process (Two Volumes), McGraw-Hill, New York.

[2] Puffer, S. (1999) ‘Global executive: Intel’s Andrew Grove on competitiveness’, Academy of Management Executive, Vol. 13, No. 1, pp 15-24.

[3] Foster, R. and Kaplan, S. (2001) Creative Destruction: Why Companies that are Built to Last Underperform the Market - and How to Successfully Transform Them, Currency, New York.

[4] Kemmis, S. (1983) 'Action research', in D. Anderson and C. Blakers (eds.), Youth, Transition and Social Research, ANU Press, Canberra. 
[5] Choo, C.W. (1998) The Knowing Organization: How Organizations Use Information to Construct Meaning, Create Knowledge, and Make Decisions, Oxford University Press, Oxford.

[6] Schrage, M. (1999) 'What's that bad odor at the skunkworks?', Fortune, Vol. 140, No. 12, pp 340.

[7] Senge, P. (1990) The Fifth Discipline: The Art and Practice of the Learning Organization, Doubleday/Currency, New York.

[8] Handy, C. (1985) Gods of Management: The Changing Work of Organizations, Pan Books, London.

[9] McCarthy, J. and McCarthy, M. (2001) Software for Your Head: Core Protocols for Creating and Maintaining Shared Vision, Addison-Wesley, Reading (Mass.).

[10] Leonard-Barton, D (1995) Wellsprings of Knowledge: Building and Sustaining the Sources of Innovation, Harvard Business School Press, Boston.

[11] Nahapiet, J. and Ghoshal, S. (1998) 'Social capital, intellectual capital, and the organizational advantage', Academy of Management Review, Vol. 23, No. 2, pp 242266.

[12] Putnam, R. (1993) Making Democracy Work: Civic Traditions in Modern Italy, Oxford University Press, New York.

[13] Dovey, K. (1997) 'The learning organization and the organization of learning: power, transformation and the search for form in learning organizations', Management Learning, Vol. 28, No. 3, pp 331-349.

[14] Nonaka, I. and Takeuchi, H. (1995) The Knowledge-Creating Company: How Japanese Companies Create the Dynamics of Innovation, Oxford University Press, Oxford. 
[15] Coleman, J. (1988) 'Social capital in the creation of human capital', American Journal of Sociology, Vol. 94, pp 95-120.

[16] Burt, R. (1997) 'The contingent value of social capital', Administrative Science Quarterly, Vol. 42, pp 339-365. 